\title{
IN-SITU RADIATION DETECTION DEMONSTRATION
}

\author{
Stephen W. Duce ${ }^{1}$, Amir H. Mohagheighi ${ }^{2}$, Mark L. Miller ${ }^{3}$, \\ Robert R. Reese ${ }^{2}$ and David R. Miller ${ }^{2}$ \\ ${ }^{1}$ IT Corporation, ${ }^{2}$ Sandia National Laboratories, ${ }^{3}$ Roy F. Weston, Inc.
}

\begin{abstract}
The Department of Defense (DoD) has hundreds of facilities where radioactive materials have been used or are being used, including firing ranges, low-level radioactive waste disposal areas, and areas where past activities have resulted in environmental contamination. Affected sites range in size from a few acres to square miles. Impact to the DoD comes through military base closure and release to the public. It is important that radioactive contaminants are remediated to levels that result in acceptable risk to the public. Remediation requires characterization studies, e.g., sampling and surveys, to define the affected areas, removal actions, and final confirmatory sampling and surveys.
\end{abstract}

Characterization of surface contamination concentrations has historically been performed using extensive soil sampling programs in conjunction with surface radiation surveys conducted with hand-held radiation monitoring equipment. Sampling is required within the suspect affected area and a large buffer area. Surface soil contaminant characterization using soil sampling and hand held monitoring are costly, time consuming, and result in long delays between submission of samples for analysis and obtaining of final results.

This project took an existing, proven radiation survey technology that has had limited exposure and improved its capabilities by documenting correlation factors for various detector/radionuclide geometries that commonly occur in field surveys. With this tool, one can perform characterization and final release surveys much more quickly than is currently possible, and have detection limits that are as good as or better than current technology.

This paper will discuss the capabilities of a large area plastic scintillation detector used in conjunction with a global positioning system (GPS) to improve site characterization, remediation, and final clearance surveys of the radioactively contaminated site. Survey results can rapidly identify areas that require remediation as well as guide surgical removal of contaminated soil that is above remediation guidelines. Post-remediation surveys can document that final radiological site conditions are within the remedial action limits.

\section{INTRODUCTION}

\section{Background Information}

The U.S. Department of Defense (DoD) has hundreds of facilities where radioactive materials have been used or are being used, including firing ranges, low-level radioactive waste disposal areas, and areas where past activities have resulted in environmental contamination. Areas like this exist at U.S. Air Force, Army, Navy and Marine bases such as Kirtland Air Force Base (AFB), Nellis AFB, Tonopah Test Range, Yucca Flats, Aberdeen Proving Grounds, China Lake Navel Air Station; and at Department of Energy (DOE) facilities such as Sandia National 
Laboratory (Sandia), Los Alamos National Laboratory, and the Nevada Test Site. Depleted uranium (DU) and radium are the dominant contaminants, and to a lesser extent, mixed fission/activation products, enriched uranium, thorium, and plutonium/americium. Affected sites range in size from a few acres to square miles.

As the DoD moves forward with military base closure or reuse, there is a responsibility to ensure that these lands and facilities have residual radioactive contamination that is at or below regulatory limits. It is important that radioactive contaminants are remediated to levels that result in acceptable future risk to the public. Also of concern are impacted, inactive, test firing areas. Here, it is important to remediate the radioactive materials from the range to reduce exposure risk to military personnel and the environment. Of concern at DOE facilities is restoration of the environment from past practices that resulted in the controlled and uncontrolled release of radioactive materials. Site remediation at these type sites requires sampling and surveys during site characterization to define the affected areas, and during corrective removal actions and final status surveys.

Characterization of surface contamination concentrations has historically been performed using extensive soil sampling programs in conjunction with surface radiation surveys conducted with hand-held radiation monitoring equipment. Selection of sampling locations has been guided in the past by professional judgement or randomly or statistically selected strategies using guidance found in draft NUREG/CR-5849, "Manual for Conducting Radiological Surveys in Support of License Termination." (Berger, 1992) [ With the advent of implementation of NUREG-1575, "Multi-Agency Radiation Survey and Site Investigation Manual (MARSSIM)" (NRC, 1997), has come a more formal process of site sampling and survey for affected areas.

Sampling is required within the suspect affected areas classified as Class 1, 2, or 3. Surface soil contaminant characterization using soil sampling and hand-held monitoring are costly, time consuming, and may result in long delays between submission of samples for analysis and obtaining of final results. Time delays due to analyses can be minimized by requesting accelerated analysis times, such as seven- to fourteen-day turn around for the submitted samples. However, there is an additional premium to be paid for expedited analysis, and the cost increase may not be warranted or justifiable. Details for this cost comparison statement can be found in the project cost and performance report (IT, 2000). Field experience has shown aerial radiation surveys for selection of sampling locations and to characterize DU have not been effective in defining the contaminant footprint, are costly, and result in long time delays to obtain final survey documentation (Adams, 1999).

The MARSSIM acknowledges emerging availability of in-situ radiation survey techniques but, unfortunately, did not have the information available at the time of publication to be prescriptive in its use. Actually, in-situ techniques are capable of providing orders-of-magnitude more data points per sample area for gamma-emitting radionuclides than would otherwise be necessary to satisfy statistical sampling designs. Significantly, these measurements are easily capable of satisfying the derived concentration guideline levels (DCGLs) established for most site cleanups. Example DCGLs are:

- 5 and 15 picocuries per gram (pCi/g) for Ra-226 in soil less than 6 inches in depth and greater than 6 inches in depth respectively, as found in Title 40 Code of Federal Regulations, Part 192 (40 CFR 192), 
- $500 \mathrm{pCi} / \mathrm{g}$ for DU at industrial sites and $250 \mathrm{pCi} / \mathrm{g}$ for DU at residential sites, as would be applied to Sandia properties, (Miller, 2000), and

- 294 and 397 pCi/g U-238 in soil less than 6 inches in depth and greater that 6 inches in depth respectively for the Linde FUSRAP site. (USACE, 1999).

These data, coupled with newly available global positioning system (GPS) data logging, make documentation and visualization of site contamination considerably better and easier than ever before.

This project has taken an existing, proven radiation survey technology, a large area plastic scintillation (LAPS) detector used in conjunction with a GPS, and improved its data presentation and evaluation capabilities by calibrating the detector response to specific radionuclides. While this study focused primarily on the LAPS detector, a sodium iodide (NaI) detector, used as a secondary detector of interest, was also characterized. Results of this NaI work are described in Appendix A.

A predictive model was developed during the scope of work that allows estimation of calibration factors for radionuclides not used in this study. With these specific radionuclide calibration factors, the DoD and others have access to a tool that can perform characterization and final release surveys more quickly than is currently possible, and final results can be directly reported in $\mathrm{pCi} / \mathrm{g}$ of soil. Thus, characterization, remediation, and final clearance surveys of a radioactively contaminated site can now be performed with a detector having detection limits that are as good as or better than current technology, as documented in this report in Section 5.0 for a high-purity germanium (HPGe) detector and Appendix A for a NaI detector. Survey results can be directly compared to required cleanup standards, allowing rapid identification of areas that require remediation or guide surgical removal of contaminated soil that is above remediation guidelines. Post-remediation surveys can document that final radiological site conditions are within the remedial action limits without requiring the extensive sampling efforts formerly used.

Performance of a field demonstration and comparison program at Kirtland AFB validated the effectiveness of the LAPS/GPS equipment. Kirtland AFB assumed the responsibility of sponsoring this demonstration and providing the field application site. Expertise from the DOE through Sandia provided needed modeling and lab verification to determine detector efficiency factors and demonstrate static and active minimum detectable activity (MDA) for various typically encountered radionuclides such as radium-226 (Ra-226), uranium-238 (U-238), and thorium-232 (Th-232). IT Corporation (IT) performed actual field verification at the Kirtland and Sandia sites using existing soil sample and in-situ gamma-spectroscopy characterization data.

\section{Project Objectives}

The demonstration plan focused on the development of calibration algorithms needed to convert the normal detector output, in counts per unit time (i.e., counts per second [cps]), to average radionuclide-specific surface contamination in $\mathrm{pCi} / \mathrm{g}$, taking into account various soil types and densities. Additionally, the algorithm was to allow for the calculation of MDA in $\mathrm{pCi} / \mathrm{g}$ for specific radionuclides and existing background at a site. Validation of the algorithms was to be demonstrated in field trials at Kirtland AFB/Sandia. 
Intermediate project objectives were to:

- Demonstrate in field trials that the detector can be used to quantitatively characterize DU soil concentrations.

- Demonstrate use of a computer model that can calculate detector efficiency factors for any gamma-emitting radionuclide distributed within a variety of soil types.

- Demonstrate that MDA limits for static and active surveys are sufficiently low to allow quantification of radioactive material that is relevant to characterization and cleanup criteria.

Achievement of these objectives provides a rapidly deployable survey tool that offers significant cost savings, improved instrument efficiencies, enhanced data collection, and support in reaching waste minimization goals during the characterization, remediation, and release surveys of large radioactively contaminated land areas.

Successful completion of these innovations was demonstrated by:

- Field tests at Site 55 and OT-91 where measured concentrations using the LAPS detector agreed well with in-situ measured concentrations and concentrations determined through soil sampling.

- Field tests, where application of the model predicted calibration factors, provided soil concentrations that were in good agreement with the as known concentrations.

- Calculation of MDAs for Sandia that were well below the DCGLs for U-238, Ra-226, and DU previously listed.

In data presentation, use of electronic data files allows great flexibility in presentation format to ensure effective communication, and documentation. Data presentation can include electronic base maps, aerial photographs, or other electronic media that allow for ease of survey data interpretation pertinent to characterization surveys, remediation activities, or post-remediation closure surveys. Determination of radionuclide-specific calibration factors allows straightforward data presentation in $\mathrm{pCi} / \mathrm{g}$ rather than nominal count rates, cps.

\section{Regulatory Issues}

Regulatory issues are based upon site remediation goals such as DCGLs discussed in the MARSSIM. These goals form the basis for the regulatory limits which apply. With base closure or free release to the public as a goal, a dose limit of 15 millirem per year (mrem/year) to a member of the public is applicable. This dose limit has been advocated by the EPA (EPA, 1990) but has been rejected by the Office of Management and Budget (Hamrick, 1999). If the prime jurisdiction comes from the Nuclear Regulatory Commission (NRC), then the limit is 25 mrem/year found in 10 CFR 20, Subpart E, "Radiological Criterion for License Termination", and if from the DOE under DOE Order 5400.5, "Radiation Protection of the Public and the Environment," $100 \mathrm{mrem} /$ year inclusive of all pathways, although DOE is also looking at 30 $\mathrm{mrem} /$ year from decommissioning of radioactive facilities. If the goal is based upon the base civilian or military personnel, then the dose limit is also $100 \mathrm{mrem} / \mathrm{year}$ as found in $10 \mathrm{CFR} 20$. 
Other applicable, relevant and appropriate guidance for many sites contaminated with uranium and radium are found in 40 CFR 192 or 10 CFR 40, Appendix A, Criterion 6(6).

In any case, residual contamination can not be allowed to reside in the near-surface soil that would result in a potentially exposed individual receiving an annual dose that exceeds the applicable limit. To this end, surveys are performed and soil samples obtained to document the residual contaminant concentrations. The detection limits for this detector have been shown to be a small fraction of the cleanup limits that would be imposed to meet the NRC's dose limit of $25 \mathrm{mrem} /$ year to a member of the public.

\section{TECHNOLOGY DESCRIPTION}

\section{Background and Application}

IT's LAPS system is composed of a 1.5-inch-thick by 3-inch-wide by 33-inch-long plastic scintillator detector that has been designed to detect greater than 300 kiloelectron volt (keV) beta particles and greater than $40 \mathrm{keV}$ gamma photons. The HHD 440A hand-held detector provides high voltage to the detector, data display, and data communication to a laptop computer. A Motorola GPS provides automatic measurement and recording of positional data for the mobile unit. The laptop computer serves as a data logger for both the detector count rate and the GPS data. A fixed-base Motorola GPS operates simultaneously with the mobile unit. GPS data collected from the base unit provide time-referenced correction factors for post-processing of field survey data having 1-meter positional accuracy. A strap-type mounting device facilitates mounting the detector on a variety of survey platforms, i.e., $4 \times 4$ vehicle, all terrain vehicle, backpacks, etc.

Application of this system relies on transporting the LAPS detector/GPS equipment over an area to be surveyed and recording the measured count rates and positional information. At the conclusion of a survey, the collected data are used with the GPS base station data to generate a graphical representation of the measured radionuclide near-surface concentrations. The choice of format is determined by client and/or regulator needs to facilitate communication of the results as clearly and as understandably as possible. Successful completion of this demonstration allows the presentation of information in $\mathrm{pCi} / \mathrm{g}$ of radionuclides known to be present rather than nominal detector count rates, cps.

Typically, the data are converted to an Arc View format to facilitate generation of a graphical presentation format. In this format, there are several format options that can be used depending upon available photographic or electronic data files. The following is a list of a few different formats that have been used in the past:

- Two-dimensional plots $(\mathrm{X}-\mathrm{Y})$

- Three-dimensional plots (X-Y-Z)

- Overlay the count-rate data on electronic base maps

- Overlay the count-rate data on a digitized aerial photo using either a digital photo or scanning a photo to convert it to a digitized format 
- Overlay the count-rate data on both an electronic base map and aerial photo

- Overlay the survey path on a digitized aerial photo and then overlay only the elevated counts on a separate digitized aerial photo

- Display the average count rate within a $10-\mathrm{m}$ by $10-\mathrm{m}$ grid

\section{Advantages and Limitations of the Technology}

As currently configured and used, this detector system provides a tool that can be used to rapidly survey large areas of radioactively contaminated land. As many as 25 acres per day have been surveyed using this technology at Norton Air Force Base, Tinker Air Force Base, and Maine Yankee Atomic Power Station. At these sites the survey results were used qualitatively to assess the presence of radioactivity above background for any contaminant, Ra-226 and Th-232, and cobalt-60 and cesium-137, respectively. This detector system has been successfully used at seven DoD, three DOE, one U. S. Army Corps of Engineers, and three commercial sites to grossly characterize radiological conditions on land areas ranging in size from 1 acre to 1,200 acres. At a nominal cost of $\$ 1500 /$ day for equipment and manpower, considerable savings over soil sampling for subsequent laboratory analysis can be achieved. For example, if the survey covered 25 acres per day (with several hundred valid data points per acre), the per-acre cost is $\$ 60$, which, when compared to a nominal cost of $\$ 125$ per sample for a gamma spectroscopy analysis, is very cost effective.

Site-specific graphical representations of these surveys have been used to guide remediation soil sampling, to demonstrate compliance with final release criteria where criteria were based upon small levels of contaminants above background, and to minimize the remediation area.

As configured and used in the past, the LAPS detector/GPS equipment could only be used to qualitatively assess the data since there were no validated correction factors to convert the count rates into quantitative units of $\mathrm{pCi} / \mathrm{g}$. With the ability to apply radionuclide-specific correction factors comes the ability to quantitatively demonstrate compliance with DCGLs.

\section{PRE-DEMONSTRATION ACTIVITIES}

Sites contaminated with radioactivity were required for field demonstration of this technology. Site selection was based upon two factors:

- The contaminant of concern must be one the LAPS detector is capable of detecting (e.g. a beta or gamma emitting radionuclide), and

- The site must have been previously characterized for that contaminant.

Kirtland AFB and Sandia have soil contaminated areas that meet both of these criteria. Sandia Site 55 was contaminated with DU. DU has the radioisotopes of uranium, U-234, U-235, and U238, and their associated radioactive decay progeny, which are easily detected with the LAPS. Kirtland AFB Site OT- 8 was "seeded" with Th-232 for training purposes, which is easily detected with the LAPS. Kirtland AFB site OT-91 was suspected of being slightly contaminated with DU. 
Concerning the second criterion, environmental studies and remedial investigations have resulted in several sites having been well characterized for DU or Th-232 in the near-surface soils.

\section{SITE/FACILITY DESCRIPTIONS}

\section{Site History}

Sandia has a major responsibility for the design and development of non-nuclear portions of weapons systems. Since the mid-1940s some operations have generated low-level radioactively contaminated environmental sites. One of the main radioactive contaminants is DU. In 1984, DOE created a site cleanup program called the Comprehensive Environmental Assessment and Response Program. Through this and subsequent programs, 157 potential waste sites at Sandia have been investigated. Three of these sites had good potential for this demonstration program; Sandia's Environmental Restoration (ER) Sites 55, Site 277/Kirtland AFB site OT-91, and Kirtland AFB Site OT-8. Site 55 is a Sandia ER Site: Site 277/Kirtland AFB Site OT-91 is a shared Sandia/Kirtland AFB site; and OT-8 is a small Kirtland AFB site.

Site 55 is a site of approximately 15 acres where residual DU is present from historical explosive testing. This area was remediated in 1995, and in May of 1998 an "extent of contamination" survey was conducted. During conduct of this survey, residual DU contamination was found. However, the small amount of remaining DU was at levels that justified a "no further action" recommendation.

Sandia ER Site 277 is a location contiguous to Kirtland AFB OT-91 located 0.5 miles due east of the Starfire Optical Range operated by Sandia. Sandia's responsibility for ER Site 277 concerns a small arroyo containing a packing crate and related debris immediately north of OT-91. Sandia is conducting sampling and investigation to identify potential contaminants on the site. Kirtland is simultaneously conducting preliminary investigative studies at OT-91 to identify potential contaminants at that site, which was used for, among other things, test-firing projectiles into a concrete wall. There is a potential for residual DU to remain on OT-91.

OT-8 was a site used by the Air Force for contaminated area site training. The site was "seeded" with Th-232 to simulate contamination from an aircraft accident around which personnel would simulate emergency response actions.

\section{FIELD VERIFICATION STUDY}

\section{Performance Objectives}

Performance objectives for this demonstration project were as follows:

- Demonstrate in field trials that the detector can be used to quantitatively characterize DU soil concentrations.

- Demonstrate use of a computer model that can calculate detector efficiency factors for any gamma-emitting radionuclide distributed within a variety of soil types. 
- Demonstrate that MDA limits for static and active surveys are sufficiently low to allow quantification of radioactive material below regulatory cleanup limits or otherwise satisfy DCGLs.

A field verification study was designed to test all of these project objectives.

\section{Demonstration Setup, Commencement, and Operation}

This project took an existing, proven radiation survey technology, owned by IT, that has had limited exposure in the DoD, DOE, and commercial sectors and developed a computer model used to provide radionuclide specific calibration factors. Sandia was responsible for characterizing the detector's performance and for model development. IT was responsible for providing the LAPS detector and a DU calibration standard, performing the field validation surveys, and preparing the final report, with input from Sandia personnel. Kirtland AFB assumed the responsibility of sponsoring this demonstration and providing the field application site at a DOD property at Kirtland AFB.

\section{TECHNICAL PERFORMANCE CRITERIA}

\section{Contaminants}

This detector system is applicable to any beta- and/or gamma-emitting radionuclide present in the near-surface soils, e.g., within the upper 12 inches of soil. The main contaminant of concern for Sandia and Kirtland AFB is DU and Th-232.

\section{Factors Affecting Technology Performance}

Detection of radionuclides in the near-surface soil column is affected by:

- Concentration of the contaminant,

- Concentration of naturally occurring radioactive materials (NORM) in the soil,

- Distribution of the contaminant in the soil column, both vertically and laterally,

- Height of the detector above the contaminated surface, and

- Rate of survey speed.

The lower the concentration of the contaminant in the soil, the harder it is to detect a measurable above-background count rate from the contaminant. The MDA for radiological monitoring equipment is affected by background, where higher NORM concentrations reduce sensitivity to the contaminants of concern, thereby increasing the MDA.

Soil acts as a shielding material for both beta particles and gamma rays. Therefore, the greater the depth from the surface, the more radioactive material must be present (more $\mathrm{pCi} / \mathrm{g}$ ) to be detected. Also, the physical surficial distribution (contaminant heterogeniety) affects detectability, where uniformly dispersed radioactive materials will result in lower MDAs than a few isolated point sources. 
An important characteristic of the large numbers of data points obtained with this method (one data point per second) is that the data points can be assembled into user-defined sub-areas of surveyed land. These data can be "pooled" to effectively lower (improve) the effective MDA.

Height of the detector will affect the field of view and also the detectability of low-energy beta particles. For a uniformly dispersed contaminant, detector height has little affect. However, if there are low-energy beta particles involved, the air between the soil surface and the detector may shield these particles from detection. If the contaminant is a point source, an increase in detector height will produce a higher MDA.

Rate of speed affects detectability and MDA. The faster a survey is conducted, the less time that the detector is over a particular location. As shown in section 5.4.4, the MDA is inversely proportional to the length of count time. Ideally, the rate of speed should be matched to the width of the viewing window, such that for every second the path length surveyed is equal to the width of the viewing window. For example, if the width of the viewing window is 7 feet, then the survey speed should be 7 feet per second, so that for every second of survey time the field of view is a $7 \times 7$ foot square. If it is desired to improve the MDA, then the survey speed should be lowered to allow more viewing time over the area to be surveyed.

\section{Reliability}

This system has shown itself to be very field-rugged and durable. Over the course of four years and many hours of surveys conducted in various types of terrain and weather, this system has had very few failures. Those failures fall into the categories of broken cables or weak auxiliary batteries.

\section{Ease of Use}

Over the four years that this system has been used, user friendliness has been improved. As currently configured, the system is very easy to configure and use in the field. There are a few improvements that can still be made to enhance user friendliness, but at the present time, are thought to be too costly for the benefit gained.

\section{Versatility}

This detector system was designed to mount easily to a wide variety of transport configurations. However, it is limited to the detection of radioactive materials that are either beta particle or gamma ray emitters, with the latter being the most important.

\section{Off-the-Shelf Procurement}

This system was procured through a specialized vendor who will custom build a detector and auxiliary hardware/software for each system. They have built several of these type systems to meet specific client requirements. They could easily reproduce a system that would be very similar to the system used in this demonstration. Any detector/rate meter combination that can satisfy the survey MDA requirements can be used when coupled with the GPS. 


\section{Maintenance}

Maintenance requirements of this system are minimal. It has been returned to the factory, on average, once per year. Average down time has been two days, one for shipping and one for repair and return. Routine maintenance involves annual detector calibration, and inspection and repair of cables.

\section{DEMONSTRATION PLAN}

\section{In-Situ Detector Calibration Method}

In 1965, in-situ gamma ray spectroscopy was initially developed by the DOE Health and Safety Laboratory (HASL) for use with sodium iodide detectors (Beck, 1968). Later, HASL expanded in-situ measurements to include HPGe detectors. Since its inception, in-situ measurements have been applied for the quantification of natural gamma emitters and associated external radiation exposure and for the quantification of man-made gamma emitters. After many years of performing specific calibrations for a wide variety of HPGe detectors, HASL personnel developed a mathematical model to calibrate HPGe detectors that simplified greatly the efforts required to calibrate an HPGe detector (Helfer, 1988).

This section describes the HASL calibration methods. In section 5.4.2, this technique is modified and applied to the LAPS detector by assuming that the detector response about the vertical axis is symmetric, the source is uniformly distributed in the horizontal plane, and that the detector area is much smaller than the source area.

The in-situ calibration factor Nf/A converts full absorption peak count rate at a given gamma ray energy to a radionuclide concentration in the soil. The in-situ calibration factor Nf/A is determined using the following equation:

$$
\mathrm{Nf} / \mathrm{A}=\mathrm{Nf} / \mathrm{No} \bullet \mathrm{No} / \varphi \bullet \varphi / \mathrm{A}
$$

where:

Nf/A (Conversion Factor):

Nf/No (Angular Response):

No/ $\varphi$ (Detector Efficiency):
Total absorption peak count rate per unit activity (cps/pCi/g)

Overall angular correction factor applied to $(\mathrm{No} / \varphi)$ to account for the fact that gamma rays in the field situation are not incident parallel to the detector axis of symmetry (unitless). Nf/No is dependent on both detector and source geometry.

Detector efficiency for gamma rays of a given energy incident on the detector parallel to the detector axis of symmetry measured in terms of the total absorption peak count rate due to a unit fluence rate of gamma rays (cps per $\gamma \bullet \mathrm{cm}^{-2} \bullet \mathrm{sec}^{-1}$ ). Dependent only on the detector. 
$\varphi$ (Fluence Rate/Concentration): $\quad$ Total fluence rate at the detector per unit soil concentration of a particular radionuclide as a function of energy, source distribution, and soil properties $\left(\gamma \bullet \mathrm{cm}^{-2} \bullet \mathrm{sec}^{-1}\right.$ per $\left.\mathrm{pCi} / \mathrm{g}\right)$.

$\varphi / \mathrm{A}$ (Fluence Rate/Activity Ratio): Ratio of the fluence rate at the detector due to gamma rays of energy $\mathrm{E}$ emitted as a result of the decay of a particular nuclide and any daughters to the corresponding radionuclide concentration in the ground $\left(\gamma \bullet \mathrm{cm}^{-2} \bullet \mathrm{sec}^{-1}\right.$ per $\left.\mathrm{pCi} / \mathrm{g}\right)$ or $\left(\gamma \bullet \mathrm{cm}^{-2} \bullet \sec ^{-1}\right.$ per $\mathrm{pCi} / \mathrm{m}^{2}$ ). Depends only on source distribution. Figure 5-1 illustrates the theoretical model for an insitu measurement. 
Figure 5-1

Theoretical Model for an In-Situ Measurement

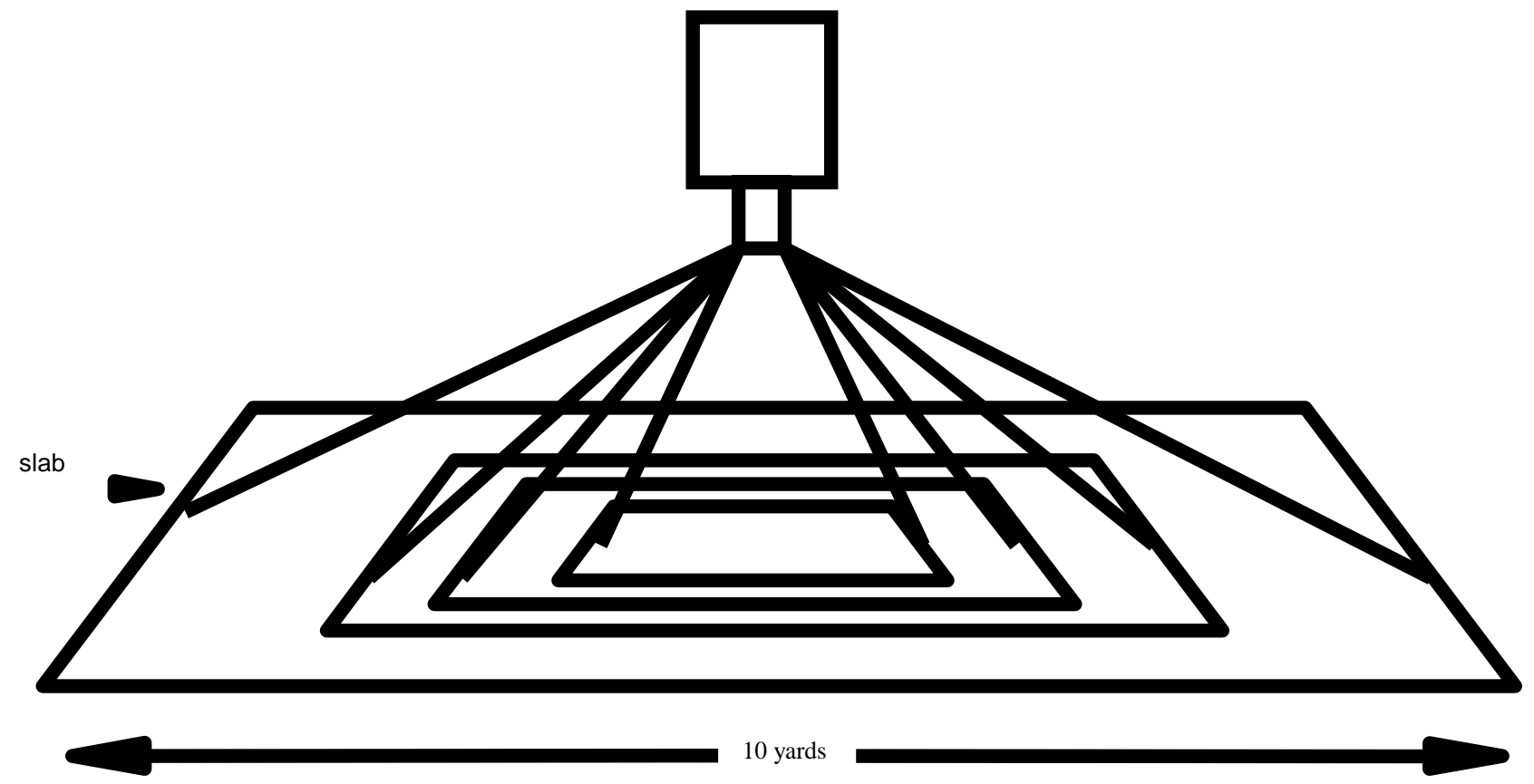

Response At Normal Incidence, $(\mathrm{No} / \varphi)$

The response at normal incidence at a given energy is determined by dividing the measured full absorption peak count rate from a gamma ray transition by the fluence rate at the average point of interaction within the crystal. Therefore, the average penetration of the photons before interaction in the medium and the estimated window to crystal distance should be considered. The average penetration distance in the absorber before a photon interaction occurs is defined as the mean free path, $\lambda$, and may be calculated using the following equation:

$$
\lambda=\int \mathrm{xe}^{-\mu \mathrm{x}} \mathrm{dx} / \int \mathrm{e}^{-\mu \mathrm{x}} \mathrm{dx}
$$

As the energy decreases and/or the thickness of the absorber increases, $\lambda$ approaches $1 / \mu$, where $\mu$ is the linear attenuation coefficient in $\mathrm{cm}^{-1}$. The manufacturer's estimated window-to-crystal distance is used in conjunction with the determination of the mean free path to estimate the average point of interaction within the crystal.

\section{Angular Response, (Nf/No)}

The angular correction factor is the angular dependence of the detector efficiency relative to the efficiency at $\theta=0^{\circ}$, weighted with the angular distribution of the gamma ray fluence rate for the depth distribution of interest. It is necessary to measure this factor since extended sources in the environment will involve detector response at angles of incidence other than normal to the 
detector face. Detector characteristics affecting the correction factor include the crystal shape and detector orientation in the field. However, for a given detector, values of Nf/No generally do not vary widely with the assumed source distribution.

The factor, Nf/No, for a particular energy and source distribution may be calculated from:

where:

$$
\mathrm{Nf} / \mathrm{No}=1 / \rho \int \varphi(\theta) / \varphi \bullet \mathrm{N}(\theta) / \mathrm{No} \mathrm{d} \theta \text { (integrating } \theta \text { from } 0 \text { to } \pi / 2 \text { ). }
$$

$\varphi(\theta) / \varphi$ (relative flux): $\quad$ The fraction of the total primary fluence rate at the angle $\theta$ for a given gamma ray energy and source distribution.

$\mathrm{N}(\theta) / \mathrm{No}$ (relative response): The response of the detector at angle $\theta$ for the same energy gamma ray relative to the response at normal incidence.

The value $\mathrm{N}(\theta)$ is determined by measuring the peak count rate at a fixed distance of at least one meter to the detector center for several angles and photon energies.

Next, the angular fluence distribution is determined by performing numerical integration from $\mathrm{w}=0$ to $\mathrm{w}=1$ using the following equation.:

where:

$$
\varphi(\mathrm{w})=\left(\alpha \mathrm{S}_{\mathrm{A}} / 2 \rho_{\mathrm{s}}\right) \bullet \exp (-\mathrm{t} / \mathrm{w}) \bullet 1 /\left[\left(\alpha / \rho_{\mathrm{s}}\right) \mathrm{w}+\left(\mu_{\mathrm{s}} / \rho_{\mathrm{s}}\right)\right]
$$

\begin{tabular}{|c|c|c|}
\hline & $=$ & detector height, $\mathrm{cm}$ \\
\hline $\mathrm{W}$ & $=$ & $\cos \theta$ \\
\hline $\mathrm{S}_{\mathrm{A}}$ & $=$ & surface activity, $\gamma \bullet \mathrm{cm}^{-2} \bullet \sec ^{-1}$ \\
\hline$x$ & $=$ & $\begin{array}{l}\text { the reciprocal of the relaxation length of the assumed exponentially } \\
\text { distributed source activity with depth, } \mathrm{cm}^{-1}\end{array}$ \\
\hline$\rho_{\mathrm{s}}$ & $=$ & soil density, $\mathrm{g} / \mathrm{cm}^{3}$ \\
\hline$\mu_{\mathrm{s}}$ & $=$ & the air and soil total gamma ray attenuation coefficients, $\mathrm{cm}^{-1}$ \\
\hline
\end{tabular}

\section{Unscattered Fluence Rate / Unit Activity Determination, ( $\varphi / A)$}

The unscattered gamma ray fluence rate at the height of the detector per unit activity concentration in soil is dependent solely on the soil density and composition, air attenuation, and source distribution of the radionuclides in the soil. For a gamma ray source of energy E, the total unscattered flux is determined by:

$$
\varphi=\int_{0}^{1} \varphi(w) d w
$$

This equation generally can not be evaluated directly but can be solved numerically. In general, natural sources of gamma radiation in the environment (U-238 series, Th-232 series, and potassium-40 [K-40] series) are assumed to be uniformly distributed in the soil, (Eisenbud, 1973) (Osburn, 1965), and represented by the equation $\mathrm{f}(\mathrm{z})=\mathrm{Sv}$, where $\mathrm{Sv}$ is the soil activity per unit volume (gamma rays per $\mathrm{cm}^{3} \bullet \mathrm{sec}$ ). In contrast, anthropogenic sources including deposition from 
weapons testing and reactor effluent in the form of fallout are reasonably approximated by the following exponential distribution:

where:

$$
\mathrm{S}(\mathrm{z})=\mathrm{S}_{\mathrm{o}} \bullet \exp (-\alpha / \rho \mathrm{s} \bullet \rho \mathrm{s} \bullet \mathrm{z})
$$

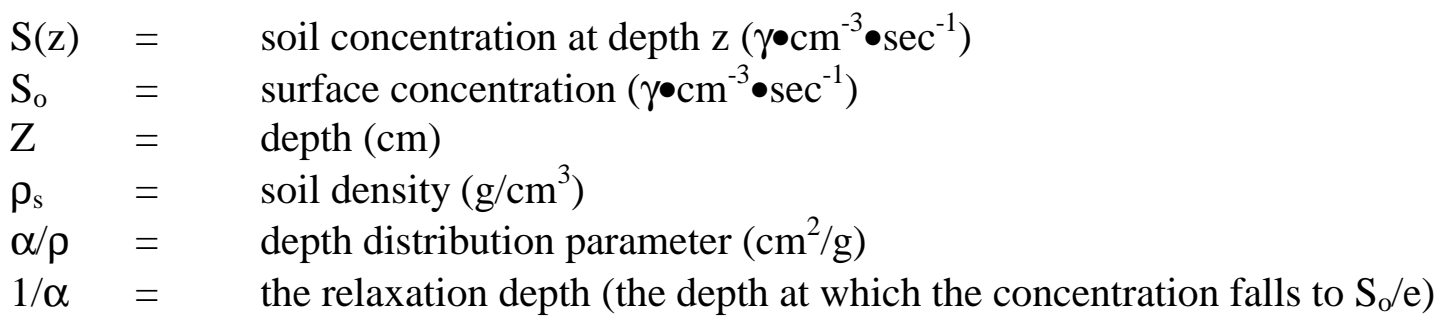

\section{Total Absorption Peak Count Rate Per Unit Activity Determination (Nf/A)}

For a uniform distribution, Nf/A is simply calculated for various gamma ray emissions by multiplying Nf/No, No/ $\varphi$, and $\varphi /$ A together.

\section{LAPS Detector Derived Calibration Factors}

The HASL method as described in section 5.4.1 is modified and applied to the LAPS detector by assuming that the detector response about the vertical axis is symmetric, the source is uniformly distributed in the horizontal plane, and that the detector area is much smaller than the source area. The main advantage of in-situ measurements is that a LAPS detector placed at $15 \mathrm{~cm}$ to 60 $\mathrm{cm}$ above the ground provides a large sampling area (for $60 \mathrm{~cm}$, approximately 2 meters by 2 meters). Also, this method averages out local inhomogeneities, is quick, and does not disturb the site. However, the accuracy of the method is dependent on the following soil parameters: density, moisture content, and chemical composition. In addition, the accuracy of the in-situ measurement is dependent on the assumed depth distribution of the radionuclides in the soil.

The LAPS detector was setup at the Sandia calibration laboratory. The Sandia and Weston personnel used four different sources (Am-241, DU, Cs-137, and Co-60) at one meter from the detector face to determine the value of $\mathrm{No} / \varphi$ at several different gamma ray energies. The known source activity along with the detector-source distance, isotope half-life, gamma ray yield, source self attenuation, and air attenuation factor were used to calculate the flux reaching the detector at each energy (Table 5-1). The gamma flux from the DU source was determined using gamma spectrometry. The effective average gamma ray energies emanating from the DU piece was determined to be $540 \mathrm{keV}$. The detector response was divided by the calculated flux to arrive at a value for $\mathrm{No} / \varphi$ at each energy. 


\section{Table 5-1}

LAPS Detector Response at Zero Degrees

\begin{tabular}{|c|c|c|c|c|c|c|c|c|}
\hline $\begin{array}{c}\text { Energy } \\
\text { (keV) }\end{array}$ & $\begin{array}{l}\text { Activity } \\
\text { (Bq) }\end{array}$ & $\begin{array}{c}\text { Branchin } \\
\mathbf{g} \\
\text { Ratio } \\
\end{array}$ & \begin{tabular}{|c|} 
Half-Life \\
(days) \\
\end{tabular} & $\begin{array}{c}\mu / \rho \text { Acrylic } \\
\left(\mathrm{cm}^{2} / \mathbf{g}\right)\end{array}$ & $\begin{array}{l}\mu / \rho \text { air } \\
\left(\mathrm{cm}^{2} / \mathbf{g}\right)\end{array}$ & $\begin{array}{c}\text { Flux } \\
\left(\gamma \mathrm{ps} / \mathrm{cm}^{2}\right)\end{array}$ & $\begin{array}{l}\text { Counts } \\
(30 \mathrm{sec})\end{array}$ & $\begin{array}{c}\mathrm{No} / \Phi \\
\mathrm{cps} /\left(\gamma \mathrm{ps} / \mathrm{cm}^{2}\right)\end{array}$ \\
\hline 59.5 & $4.150 \mathrm{E}+05$ & 0.3570 & 157753 & 0.1980 & 0.1770 & $1.075 \mathrm{E}+00$ & 4470 & $1.386 \mathrm{E}+02$ \\
\hline DU & $1.336 \mathrm{E}+04$ & 1.0000 & $1.63 \mathrm{E}+12$ & 0.1018 & 0.0916 & $1.004 \mathrm{E}-01$ & 2430 & $8.066 \mathrm{E}+02$ \\
\hline 661.7 & $3.980 \mathrm{E}+04$ & 0.8521 & 11012 & 0.0886 & 0.0774 & $2.719 \mathrm{E}+00$ & 7290 & $8.938 \mathrm{E}+01$ \\
\hline 1253.0 & $3.660 \mathrm{E}+04$ & 2.0000 & 1924 & 0.0677 & 0.0609 & $5.570 \mathrm{E}-01$ & 8460 & $5.063 E+02$ \\
\hline & & & $\begin{array}{r}\mathrm{k} \epsilon \\
\gamma p s- \\
\mathrm{cp} \\
\text { LAPS - }\end{array}$ & $\begin{array}{r}\text { - kiloelect } \\
\text { Bq - Becq } \\
\text { g - gram } \\
\text { - centim } \\
\text { amma rays } \\
\text { - counts pe } \\
\text { rge area pl }\end{array}$ & $\begin{array}{l}\text { n volts } \\
\text { rel } \\
\text { ters } \\
\text { er secono } \\
\text { second } \\
\text { tic scintill }\end{array}$ & & & \\
\hline
\end{tabular}

The value $\mathrm{N}(\theta)$ was determined by measuring the source count rate at a distance of one meter at 15-degree intervals. Figure 5-2 shows the laboratory setup used in the performance of these measurements. Table 5-2 lists the LAPS relative angular response.

Figure 5-2

Laboratory Setup for LAPS

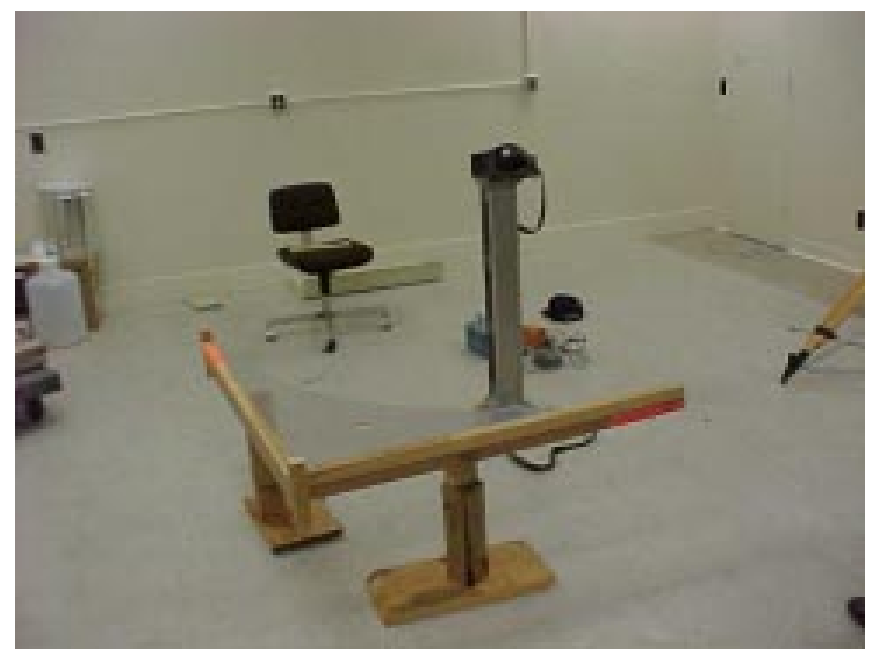


Table 5-2

LAPS Detector Relative Angular Response

\begin{tabular}{|c|c|c|c|c|}
\hline Anale & $60 \mathrm{keV}$ & DU & 662 & 1253 \\
\hline 0 & 1.00 & 1.00 & 1.00 & 1.00 \\
\hline 15 & 0.87 & 0.91 & 0.93 & 0.98 \\
\hline 30 & 0.82 & 0.74 & 0.88 & 0.96 \\
\hline 45 & 0.60 & 0.57 & 0.84 & 0.88 \\
\hline 60 & 0.41 & 0.59 & 0.77 & 0.85 \\
\hline 75 & 0.20 & 0.47 & 0.79 & 0.83 \\
\hline 90 & 0.00 & 0.30 & 0.67 & 0.76 \\
\hline
\end{tabular}

The relative flux reaching the detector at different angles for a uniform distribution, detector height of $30 \mathrm{~cm}$, and a soil density of $2.0 \mathrm{~g} / \mathrm{cm}^{3}$, was numerically calculated and summarized in Table 5-3.

Table 5-3

Relative Angular Flux for Uniformly Distributed Source

\begin{tabular}{|c|c|c|c|c|}
\hline Angle & $\begin{array}{c}\mathbf{6 0} \\
\mathbf{k e V}\end{array}$ & $\begin{array}{c}\mathbf{D U} \\
\mathbf{k e V}\end{array}$ & $\begin{array}{c}\mathbf{6 6 2} \\
\mathbf{k e V}\end{array}$ & $\begin{array}{c}\mathbf{1 2 5 3} \\
\mathbf{k e V}\end{array}$ \\
\hline $0-15$ & 0.0410 & 0.0405 & 0.0405 & 0.0404 \\
\hline $15-30$ & 0.1024 & 0.1012 & 0.1011 & 0.1009 \\
\hline $30-45$ & 0.1637 & 0.1619 & 0.1617 & 0.1614 \\
\hline $45-60$ & 0.2092 & 0.2072 & 0.2070 & 0.2066 \\
\hline $60-75$ & 0.2485 & 0.2469 & 0.2467 & 0.2464 \\
\hline $75-90$ & 0.2353 & 0.2424 & 0.2430 & 0.2444 \\
\hline Total & 1.0000 & 1.0000 & 1.0000 & 1.0000 \\
\hline \multicolumn{5}{|c|}{ keV - kiloelectron volt } \\
DU - depleted uranium
\end{tabular}

The factor, $\mathrm{N}_{\mathrm{f}} / \mathrm{N}_{\mathrm{o}}$, was calculated by multiplying the relative detector response by the relative angular flux for each angle and summing the results for each energy. The results are summarized in Table 5-4.

Table 5-4

Angular Correction Factors $\left(\mathbf{N}_{\mathrm{f}} / \mathrm{N}_{\mathrm{o}}\right)$

\begin{tabular}{|c|c|c|c|c|}
\hline Energy & $\begin{array}{c}60 \\
\mathbf{k e V}\end{array}$ & $\begin{array}{c}\mathrm{DU} \\
\mathbf{k e V}\end{array}$ & $\begin{array}{c}662 \\
\mathbf{k e V}\end{array}$ & $\begin{array}{c}1253 \\
\mathbf{k e V}\end{array}$ \\
\hline $\mathrm{N}_{f} / \mathrm{N}_{0}$ & 0.45 & 0.57 & 0.80 & 0.87 \\
\hline \multicolumn{6}{c}{$\mathrm{keV}-$ kilo electron volts } \\
$\mathrm{DU}$ - depleted uranium \\
gps - gamma rays per second
\end{tabular}


The total flux reaching the detector for a uniform distribution, detector height of $30 \mathrm{~cm}$, and a soil density of $2.0 \mathrm{~g} / \mathrm{cm}^{3}$, was numerically calculated and are summarized in Table 5-5.

Table 5-5

Total Flux At Detector Position

\begin{tabular}{|c|c|c|c|c|}
\hline Energy & $\begin{array}{c}60 \\
\mathbf{k e V}\end{array}$ & $\begin{array}{c}\text { DU } \\
\mathbf{k e V}\end{array}$ & $\begin{array}{c}\mathbf{6 6 2} \\
\mathbf{k e V}\end{array}$ & $\mathbf{1 2 5 3}$ \\
\hline$\Phi / \mathrm{A}\left(\mathrm{gps} / \mathrm{cm}^{2}\right) /(\mathrm{gps} / \mathrm{g})$ & 1.9567 & 5.7738 & 6.3137 & 8.0801 \\
\hline \multicolumn{4}{r|}{$\mathrm{keV}-$ kilo electron volts } \\
DU - depleted uranium \\
gps - gamma rays per second
\end{tabular}

Finally, the $\mathrm{N}_{\mathrm{f}} / \mathrm{A}$ values by gamma ray energy were calculated by multiplying $\mathrm{Nf} / \mathrm{No}, \mathrm{No} / \varphi$, and $\varphi /$ A values together as listed on Table 5-6.

\section{Table 5-6}

Derived Calibration Factors

\begin{tabular}{|c|c|c|c|c|}
\hline $\begin{array}{c}\text { Energy } \\
(\mathbf{k e V})\end{array}$ & $\begin{array}{c}\mathbf{N}_{\mathbf{o}} / \Phi \\
\mathbf{c p s} /\left(\mathbf{g p s} / \mathbf{c m}^{2}\right)\end{array}$ & $\mathbf{N}_{\mathbf{f}} / \mathbf{N}_{\mathbf{o}}$ & $\begin{array}{c}\Phi / \mathbf{A} \\
\left(\mathbf{g p s} / \mathbf{c m}^{2}\right) /(\mathbf{g p s} / \mathbf{g})\end{array}$ & $\begin{array}{c}\mathbf{N}_{\mathbf{f}} / \mathbf{A} \\
\mathbf{c p s} / \mathbf{g p s} / \mathbf{g})\end{array}$ \\
\hline 60 & 139 & 0.45 & 1.9567 & $1.211 \mathrm{E}+02$ \\
\hline $\mathrm{DU}$ & 807 & 0.57 & 5.7738 & $2.666 \mathrm{E}+03$ \\
\hline 662 & 89 & 0.80 & 6.3137 & $4.542 \mathrm{E}+02$ \\
\hline 1253 & 506 & 0.87 & 8.0801 & $3.541 \mathrm{E}+03$ \\
\hline \multicolumn{4}{|r|}{$\mathrm{keV}-$ kiloelectron volt } \\
cps - counts per second \\
DU - depleted uranium \\
gps - gamma rays per second \\
g-grams
\end{tabular}

As an example, applying the gamma yield fractions for DU, we find a calibration factor of 10.5 $\mathrm{cps} / \mathrm{pCi} / \mathrm{g}$ for the assumed conditions. Users of this methodology are reminded that site-specific calibration factors may be determined at every different site surveyed. Best results are obtained when the modeled source distribution is similar to the actual source distribution. In the future, exponential models and overburden models could be used to more accurately assess contaminated areas with non-uniformly distributed radionuclides.

\section{Empirical Calibration Factors}

Sandia personnel took the LAPS detector to Grand Junction, Colorado, where field calibrations were performed using the DOE's large-area calibration pads. These pads, located at the Walker Field Airport, are five concrete pads having dimensions of 40 feet wide, 30 feet long, and 1.5 feet thick. Four of the pads have been uniformly spiked to known concentrations of Ra-226, Th-232, or K-40. The remaining pad has NORM, which are at typical background concentrations.

Information concerning these calibration pads is included in Table 5-7. In-situ gamma ray spectroscopy measurements were made with a HPGe detector on each pad, as shown in Figure 53. Although not directly applicable to this study, it was felt that these HPGe measurements would validate the field measurement techniques used to establish source concentrations at the 
Sandia/Kirtland AFB sites. Further they would enhance overall project objectives for Sandia and Kirtland AFB. Both the documented concentration (known) and the observed in-situ gamma spectroscopy confirmatory values determined during the field calibration are listed in Table 5-7. These data show good agreement between the known and in-situ measured values, thus validating the calibration software and technique for the HPGe.

Table 5-7

Known and Measured Pad Activities (pCi/g)

\begin{tabular}{|c|c|c|c|c|}
\hline Pad ID & $\begin{array}{c}\text { Known Ra-226 } \\
\text { Activity }\end{array}$ & Uncertainty & $\begin{array}{c}\text { In-Situ Ra-226 } \\
\text { Activity }\end{array}$ & Uncertainty \\
\hline W1 & 0.82 & 1.02 & 1.17 & 0.19 \\
\hline W2 & 1.92 & 1.54 & 1.81 & 0.28 \\
\hline W3 & 1.70 & 1.38 & 1.53 & 0.25 \\
\hline W4 & 12.07 & 5.64 & 9.60 & 1.33 \\
\hline W5 & 8.36 & 3.62 & 6.40 & 0.90 \\
\hline & & & & \\
\hline & & & In-Situ Th-232 & Activity \\
Pad ID & Activity & Uncertainty & 0.69 & 0.38 \\
\hline W1 & 0.67 & 0.10 & 1.20 & 0.66 \\
\hline W2 & 0.87 & 0.12 & 4.22 & 1.90 \\
\hline W3 & 4.92 & 0.26 & 1.11 & 0.50 \\
\hline W4 & 1.04 & 0.12 & 2.27 & 1.33 \\
\hline W5 & 1.91 & 0.16 & & \\
\hline & & & In-Situ K-40 & \\
\hline & Known K-40 & & 12.3 & 1.8 \\
\hline Pad ID & Activity & Uncertainty & Activity & Uncertainty \\
\hline W1 & 12.67 & 0.72 & 55.6 & 8.0 \\
\hline W2 & 45.58 & 1.82 & 17.1 & 2.5 \\
\hline W3 & 17.07 & 0.82 & 23.7 & 3.5 \\
\hline W4 & 17.56 & 0.98 & 46.3 & 6.71 \\
\hline W5 & 34.68 & 1.48 & & \\
\hline & & & & \\
\hline
\end{tabular}




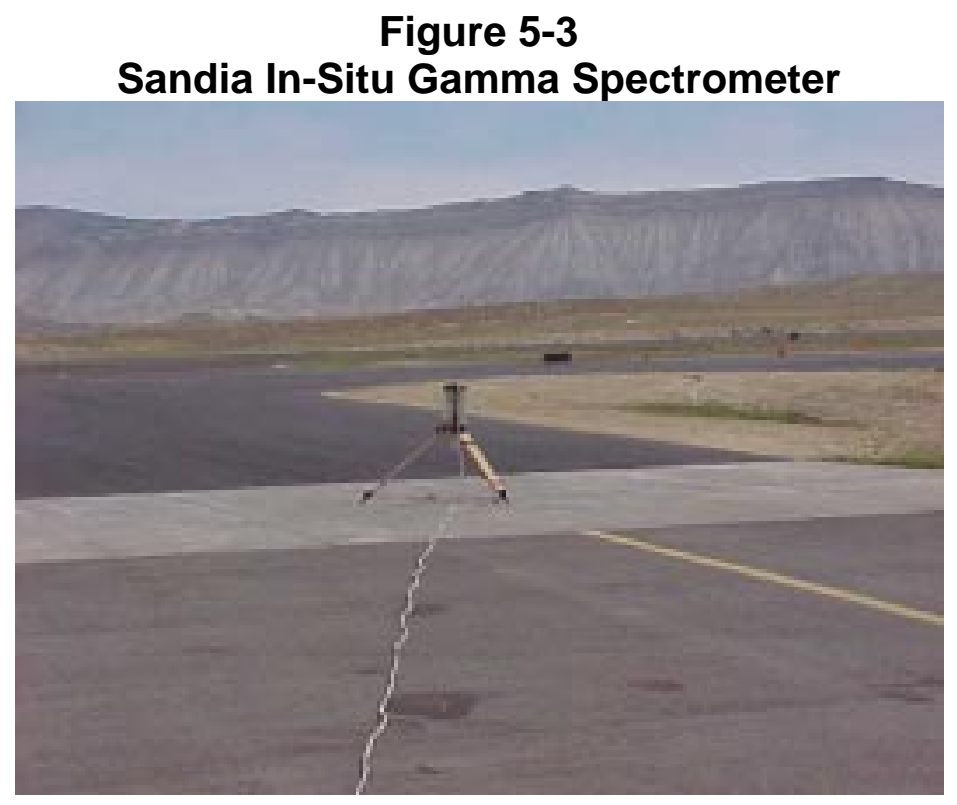

The next set of measurements made at the DOE Calibration Pads used the LAPS detector. Field personnel suspended the LAPS detector above the center point of the pad. Low-density material was used to suspend the detector to minimize any attenuation of gamma rays that may potentially be shielded by the support material.

Three detector heights were investigated, 6 inches $(15 \mathrm{~cm}), 12$ inches $(30 \mathrm{~cm})$, and 20 inches $(51$ $\mathrm{cm})$ above the pad surface. These three distances are typical of detector survey heights used. Distances were measured from the face of the detector to the pad surface. At each height, a sufficient number of one-second count rates were measured and recorded to allow for a 95 percent confidence factor that the true mean count rate had been determined. Once these count rates were measured at all three heights for the first pad, the equipment was set up on another pad and the procedure repeated. Average count rates and uncertainties are listed in Table 5-8 for each detector height and pad.

Table 5-8

LAPS Detector Readings for the Different Pads

\begin{tabular}{|c|c|c|c|c|}
\hline Pad ID & cps at 6 inches & $\begin{array}{c}\text { cps at 12 } \\
\text { inches }\end{array}$ & $\begin{array}{c}\text { cps at 20 } \\
\text { inches }\end{array}$ & Average cps \\
\hline W1 & $458 \pm 48$ & $449 \pm 48$ & $452 \pm 44$ & $453 \pm 27$ \\
\hline W2 & $902 \pm 58$ & $899 \pm 66$ & $862 \pm 68$ & $888 \pm 22$ \\
\hline W3 & $1275 \pm 72$ & $1275 \pm 54$ & $1240 \pm 64$ & $1263 \pm 20$ \\
\hline W4 & $1750 \pm 84$ & $1711 \pm 94$ & $1622 \pm 72$ & $1694 \pm 66$ \\
\hline W5 & $1662 \pm 80$ & $1650 \pm 82$ & $1594 \pm 58$ & $1653 \pm 36$ \\
\hline \multicolumn{4}{r}{ cps - counts per second } \\
\hline \multicolumn{4}{r|}{ LAPS - large area plastic scintillator } \\
\hline
\end{tabular}

The measured results showed little variation with height over the range of heights tested. This is expected as the source is infinite as seen from the detector vantage point. Thus, detector height determines the coverage area and the associated detection limits, but over the range of heights tested, adds little variability in the detection and quantification of the radioactivity. 
Calibration factors, in cps/pCi/g, were calculated for each of the three spike radionuclides, Ra226, Th-232, and K-40 using the source concentrations and background count rates from Table 5-8. The observed detector responses at 12 inches for the five pads were fitted to the following mathematical model to arrive at the calibration factors:

where:

$$
\text { cps }=\mathrm{B}+\mathrm{A}_{\mathrm{R}} * \mathrm{C}_{\mathrm{R}}+\mathrm{A}_{\mathrm{T}} * \mathrm{C}_{\mathrm{T}}+\mathrm{A}_{\mathrm{K}} * \mathrm{C}_{\mathrm{K}}
$$

$$
\begin{array}{lll}
\mathrm{B} & = & \text { the inherent detector background, } \\
\mathrm{A}_{\mathrm{R}}, \mathrm{A}_{\mathrm{T}}, \mathrm{A}_{\mathrm{K}}= & \text { the known activities for Ra-226, Th-232, and K-40, and } \\
\mathrm{C}_{\mathrm{R}}, \mathrm{C}_{\mathrm{T}}, \mathrm{C}_{\mathrm{K}}= & \text { the calibration factors for Ra-226, Th-232, and K-40. }
\end{array}
$$

The fitting process was performed by a computer where the calibration factors were iteratively adjusted until the differences between the predicted and observed values, as measured by the reduced Chi-Squared $\left(\mathrm{Chi}^{2}\right)$ test, were minimized. The reduced $\mathrm{Chi}^{2}$ value is 0.03 indicating that the mathematical equation adequately models the detector response. The calibration factors are summarized in Table 5-9 and a graphical representation is shown in Figure 5-4. As a second check on the empirical calibration factors, the known concentrations of each pad were used to predict what count rate should have been observed. The predicted and observed count rates are also listed in Table 5-9. The agreement between the as measured and predicted values show that the empirical calibration factors have been adequately fit to the data.

Figure 5-4

Comparison of Predicted and Observed Values

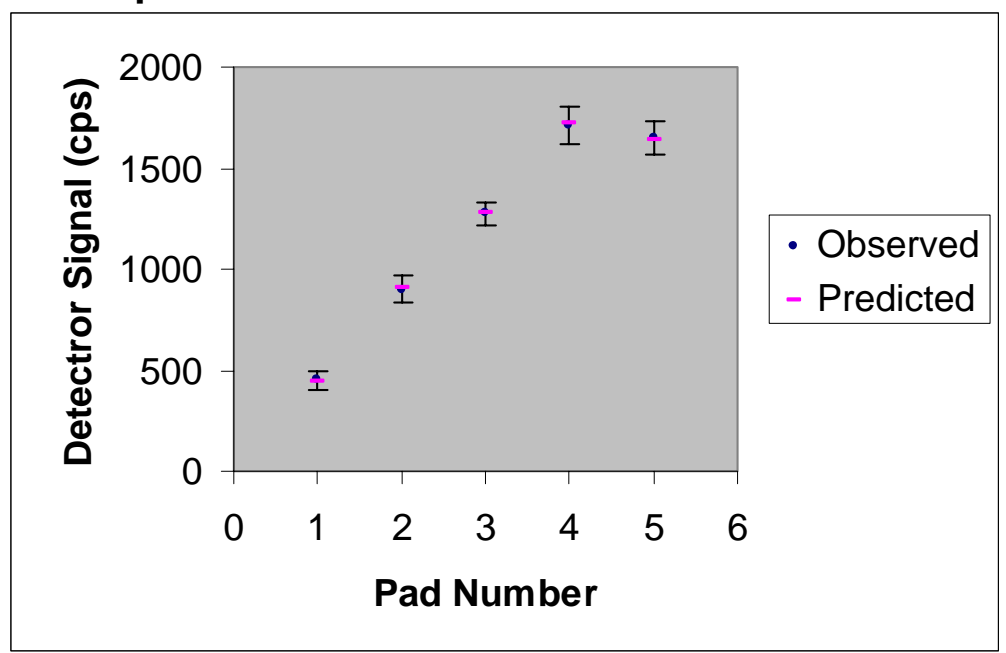


Table 5-9

Empirical Calibration Factors

\begin{tabular}{|l|c|l|l|l|c|}
\hline Detector Background & 135 & $\mathrm{cps}$ & & \\
\hline Ra-226 Calibration Factor & 104 & $\mathrm{cps} / \mathrm{pCi} / \mathrm{g}$ & & \\
\hline Th-232 Calibration Factor & 164 & $\mathrm{cps} / \mathrm{pCi} / \mathrm{g}$ & & & \\
\hline K-40 Calibration Factor & 9.4 & $\mathrm{cps} / \mathrm{pCi} / \mathrm{g}$ & & & \\
\hline & Pad W1 & Pad W1 & Pad W3 & Pad W4 & Pad W5 \\
\hline Predicted cps & 448 & 903 & 1276 & 1720 & 1638 \\
\hline Observed cps at 12 inches & 449 & 899 & 1275 & 1711 & 1650 \\
\hline
\end{tabular}

\section{MDA Calculations}

The MDA for a static measurement is defined as "the smallest value of true activity such that a measured activity can be expected, with a given degree of confidence ...to imply correctly that true activity is greater than zero." (Altshuler, 1963) Or stated a little differently, MDA is the lowest quantity of radioactivity that if present in a source or sample would be detected with a 95 percent confidence factor. Mathematically it is given by Curie (Curie, 1968) as:

$$
M D A=\frac{4.66 \sqrt{B / T}+3}{F}
$$

where:

$$
\begin{array}{lll}
\mathrm{MDA} & = & \text { minimum detectable activity in } \mathrm{pCi} / \mathrm{g} \\
\mathrm{B} & = & \text { the background count rate in cps, } \\
\mathrm{T} & = & \text { the count time in seconds, and } \\
\mathrm{F} & = & \text { the calibration factor in } \mathrm{cps} / \mathrm{pCi} / \mathrm{g} .
\end{array}
$$

This equation is applicable for MDA calculations for all counting systems, even low background counting systems. However, for areas with large background, such as the sites discussed herein, the " 3 " becomes insignificant when compared with background count rates. Therefore, for further application, the equation becomes:

where:

$$
M D A=\frac{4.66 \sqrt{B / T}}{F}
$$

$\begin{array}{lll}\mathrm{MDA} & = & \text { minimum detectable activity in } \mathrm{pCi} / \mathrm{g}, \\ \mathrm{B} & = & \text { the background count rate in cps, } \\ \mathrm{T} & = & \text { the count time in seconds, and } \\ \mathrm{F} & = & \text { the calibration factor in cps/pCig. }\end{array}$

For example, at Site 55 the background count rate for a nearly contaminated area was $594 \mathrm{cps}$. Using a count time of one second and calibration factor of $10.5 \mathrm{cps} / \mathrm{pCi} / \mathrm{g}$ for DU (see Section 5.4.2), the MDA is $10.8 \mathrm{pCi} / \mathrm{g}$. This MDA is well below the typical remediation cleanup goal of $35 \mathrm{pCi} / \mathrm{g}$, as well as the cleanup goals for total uranium being used for cleanup of sites that fall under the Formerly Utilized Sites Remedial Action Program. These goals range from 35 to hundreds of $\mathrm{pCi} / \mathrm{g}$. 
The static MDA equation was modified for moving scans by breaking the scan into a series of static measurements. The count time is now given by:

$$
\mathrm{T}=\mathrm{X} / \mathrm{V}
$$

where:

$\mathrm{T}=$ the effective count time for a section in seconds,

$\mathrm{X}=\quad$ the detector linear foot print along the direction of travel in meters, and $\mathrm{V}=$ the scan speed in meters per second.

The detector footprint is the distance along the direction of travel where the detector is capable of detecting a signal. This parameter was determined experimentally at the Sandia calibration laboratory by placing the detector at 20 inches above the ground surface and moving a source along the direction of travel. The results are summarized in Table 5-10. 
Table 5-10

Linear Detector Footprint (along the direction of travel)

\begin{tabular}{|c|c|c|c|}
\hline $\begin{array}{c}\text { Distance } \\
\text { (feet) }\end{array}$ & $\begin{array}{c}\text { Net } \\
\text { Counts }\end{array}$ & $\begin{array}{c}\text { Relative } \\
\text { Response }\end{array}$ & Angle \\
\hline 0 & 3498 & 1.00 & 00.00 \\
\hline 1 & 2704 & 0.77 & 30.96 \\
\hline 2 & 1567 & 0.45 & 50.19 \\
\hline 3 & 841 & 0.24 & 60.95 \\
\hline 4 & 529 & 0.15 & 67.38 \\
\hline 5 & 367 & 0.10 & 71.57 \\
\hline 6 & 261 & 0.07 & 74.48 \\
\hline 6 & 261 & 0.07 & 74.48 \\
\hline 7 & 203 & 0.06 & 76.61 \\
\hline 8 & 178 & 0.05 & 78.23 \\
\hline 9 & 144 & 0.04 & 79.51 \\
\hline 10 & 125 & 0.04 & 80.54 \\
\hline
\end{tabular}

Taking a conservative stance by setting the cut-off point where detector response falls below 25 percent, the foot print angle is set to $60^{\circ}$. The detector footprint, $\mathrm{X}$, is given by

resulting in

$$
X=0.0762+2 * H * \tan (60)
$$

where:

$$
\mathrm{X}=0.0762+3.46 * \mathrm{H}
$$

$$
\mathrm{H}=\text { detector height in meters. }
$$

Finally, the MDA equation for a moving scan with the LAPS detector is given by:

$$
M D A=\frac{4.66 \sqrt{\frac{B * V}{0.0762+3.46 * H}}}{F}
$$

The MDA values for different scan speeds and radionuclides for typical field conditions are presented in Table 5-11. 
Table 5-11

Typical Scanning MDA Values in $\mathrm{pCi} / \mathrm{g}$ for the LAPS

\begin{tabular}{|c|c|c|c|c|}
\hline Scan Speed (mph) & Static & 2 & 4 & 8 \\
\hline Scan Speed (m/s) & Static & 0.9 & 1.8 & 3.6 \\
\hline Detector Height $(\mathrm{cm}$ & 30 & 30 & 30 & 30 \\
\hline Ra-226 MDA & 1.1 & 1.0 & 1.3 & 1.9 \\
\hline Th-232 MDA & 0.6 & 0.6 & 0.8 & 1.1 \\
\hline $\mathrm{K}-40 \mathrm{MDA}$ & 9.2 & 8.2 & 11.6 & 16.4 \\
\hline DU MDA & 10.8 & 9.7 & 13.7 & 19.4 \\
\hline & $\begin{array}{l}\text { leted uran } \\
\text { arge area } \\
\text { inimum de } \\
\text { iles per ho } \\
\text { ters per s } \\
\text { icocuries }\end{array}$ & $\begin{array}{l}\text { scin } \\
\text { ple ac }\end{array}$ & & \\
\hline
\end{tabular}

\section{Field Demonstration}

Once both laboratory and field calibration factors were established, the Kirtland AFB/Sandia field demonstration was performed. Following the laboratory and field calibration activities, a Kirtland AFB/Sandia site whose DU surface soil concentrations have been characterized by traditional soil sampling methods and non-traditional in-situ gamma spectroscopy, were selected for field trials. Field trials, supported by IT and Sandia, consisted of the following activities.

- Performing static counts at areas where soil samples were obtained or in-situ gamma spectroscopy.

- Performing drive-over surveys of the selected site(s), using a near-100-percent coverage.

- Generating estimates of the "as-measured" radioactivity concentrations using the predicted efficiency factor.

- Comparing the estimates to the concentrations determined from soil sampling or in-situ HPGe measurements.

It was anticipated that some variance in surface concentrations would be observed due to the differences found when using discrete soil sampling techniques, in-situ gamma spectroscopy, and the LAPS detector. Both IT and Sandia project personnel evaluated the differences and determined their significance. In the case of the data found in Table 5-12 for ER Site 55 the LAPS and HPGe measurements both show results that are at or below the detection limit as indicated by the large uncertainties in the LAPS activity, and the "ND" listed for the HPGe detector. The laboratory results list values that are below the detection limit for both in-situ methods, thus indicating agreement at least at the method detection limits. Table 5-13 shows good agreement between the LAPS concentrations and the HPGe measured concentrations. 
Table 5-12

Sandia Environmental Restoration Site 55 Field Measurements

\begin{tabular}{|l|c|c|c|c|c|}
\hline & Bkg & Grid 1 & Grid 2 & Grid 3 & Grid 4 \\
\hline Average cps & $\mathbf{5 8 9}$ & $\mathbf{6 6 6}$ & 666 & 644 & 648 \\
\hline Uncertainty & 45 & 63 & 42 & 59 & 36 \\
\hline Estimated DU Activity (pCi/g) & - & 7.3 & 7.3 & 5.2 & 5.6 \\
\hline Uncertainty & - & 7.4 & 5.9 & 7.1 & 5.5 \\
\hline In-Situ HPGe Detector & - & ND & ND & ND & ND \\
\hline Laboratory Results & - & 2.0 & 1.0 & 0.9 & 1.0 \\
\hline Uncertainty & - & 0.4 & 0.6 & 0.4 & 0.3 \\
\hline & Bkg - background \\
cps - counts per second \\
DU - depleted uranium \\
HPGe - high purity germanium detector \\
ND - no data \\
pCi/g - picocuries per gram
\end{tabular}

\section{ER Site 55 Study}

At the Sandia facility there are several sites where previous soil sampling and in-situ gamma spectroscopy measurements have characterized the residual contamination. One such site is ER Site 55. This site had been previously contaminated with DU while performing simulated nuclear weapons accident scenarios. In the 1990s, this site was remediated by performing walkover surveys of the area with 2-in by 2-in NaI detectors. DU fragments were gathered as they were found. Once all DU fragments had been found, the site was considered cleaned. However, there were some areas that exhibited elevated count rates even though no DU fragments could be found. These areas were generally in low-lying areas where the weathering process of water erosion would have transported the soil-sized DU-oxide fines, or where the initial deposition resulted in small soil-like DU fines.

Several surveys have been conducted at ER Site 55 by Sandia's Environmental Restoration Group, and subcontractors. Soil samples and in-situ gamma spectroscopy have been used to characterize the final residual contamination. In the drainage area four DU test areas were identified to establish the as-found DU concentrations. DU concentrations ranged within these four test areas from background (approximately $1 \mathrm{pCi} / \mathrm{g}$ ) to $2 \mathrm{pCi} / \mathrm{g}$.

In September 1999, the LAPS detector system was used at ER Site 55 to measure the count rate from each of the four test areas. Then, using the collected count rate data and the correlation factor determined by the calibration model, the DU concentration was estimated. Table 5-12 shows the gross count rate, net count rate, predicted DU concentration, and measured DU concentration at the center point of each test area. Also listed are the in-situ HPGe and soil sampling results. As can be seen all of the detector values are below the estimated MDA for these measurements. The soil results are at concentrations that are consistent with the MDA's for the LAPS and the HPGe detectors.

The DU MDAs for static and moving measurements listed in Table 5-11 are well below the typical remediation cleanup goal of $35 \mathrm{pCi} / \mathrm{g}$, as well as the cleanup goals for total uranium being 
used for cleanup of sites that fall under the Formerly Utilized Sites Remedial Action Program. These goals range from 35 to hundreds of $\mathrm{pCi} / \mathrm{g}$.

ER Site 55 had been previously surveyed using the LAPS detector during the spring of 1999. The collected count rate data were averaged over $10-\mathrm{m}$ by $10-\mathrm{m}$ grids and the currently determined calibration factor of $10.5 \mathrm{cps} / \mathrm{pCi} / \mathrm{g}$ was applied to the measured data. There are several regions within ER Site 55 that show elevated DU concentrations that range between 0-5 $\mathrm{pCi} / \mathrm{g}$ and 5-10 pCi/g. However, these findings do not conflict with the results of the four static measurements previously described, but rather show the added benefit that is gained by having a significantly larger number of data points to "pool" in the determination of the presence of above natural background radioactivity. These data were obtained while driving the detector over the site at speeds between 2 to 4 miles per hour. At these speeds, the predicted MDAs listed in Table 5-11 are 10 and $14 \mathrm{pCi} / \mathrm{g}$, respectively. However, by using a larger sample size, i.e., more counts in the pooled data set, the effective MDA is lowered by nearly a factor of two to $5 \mathrm{pCi} / \mathrm{g}$. Thus, MDAs can be improved by the collection and pooling of more data points.

Similar measurements were made at KAFB Site OT-8, which was seeded with Th-232 for training purposes, and KAFB Site OT-91, which was suspected to have DU present from projectile testing that occurred at the site. The following discussion shows site conditions during the survey and the predicted near-surface concentrations of Th-232 and DU at sites OT-8 and OT-91, respectively.

\section{Kirtland AFB OT-8}

Four locations were selected at the OT-8 site for making in-situ measurements with the HPGe and the LAPS detector. Table 5-13 shows the results of this comparison study. Both sets of measured results are in excellent agreement, with the reported value uncertainties overlapping. However, the jogger cart tended to "under-predict" the amount of Th-232 present.

Table 5-13

OT-8 Field Measurements

\begin{tabular}{|c|c|c|c|c|c|}
\hline & Bkg & Grid 1 & Grid 2 & Grid 3 & Grid 4 \\
\hline Average cps & 630 & 948 & 3220 & 938 & 1788 \\
\hline Uncertainty & 57 & 57 & 381 & 48 & 68 \\
\hline Estimated Th-232 Activity (pCi/g) & - & 1.9 & 15.8 & 1.9 & 7.1 \\
\hline Uncertainty & - & 0.5 & 2.4 & 0.5 & 0.5 \\
\hline In-Situ HPGe Detector & $\begin{array}{ll}- \\
-\end{array}$ & 4.9 & 21.5 & 4.0 & 13.8 \\
\hline Uncertainty & - & 2.2 & 9.5 & 1.8 & 6.2 \\
\hline
\end{tabular}

Following these static measurements, the LAPS detector was mounted on the bumper of a fourwheel-drive sport utility vehicle (SUV). For this configuration, the detector was driven over the OT-8 site. 


\section{Kirtland AFB/Sandia OT-91}

A drive-over survey of approximately four acres was conducted at OT-91 with the LAPS detector mounted to the bumper of a four-wheel drive SUV. Areas having higher count rates were identified and the approximate center located. The LAPS detector was held static over these sites and the count rates were recorded. A second researcher used a 2-in by 2-in NaI detector to overwalk these high count rate areas. As a final step, the HPGe detector was used to determine the soil contaminant radionuclide and concentration.

The comparison results of the LAPS and HPGe calculated concentrations show good agreement. The in-situ HPGe measurement yielded an average DU value of $45 \pm 9 \mathrm{pCi} / \mathrm{g}$. The LAPS detector had an average reading of $1130 \mathrm{cps}$. Subtracting a background of $602 \mathrm{cps}$ and applying the 10.5 calibration factor, a DU activity of $50 \pm 8 \mathrm{pCi} / \mathrm{g}$ is obtained. This is in excellent agreement with the in-situ HPGe value.

The LAPS count rates were converted from cps to $\mathrm{pCi} / \mathrm{g}$; averaged over $10-\mathrm{m}$ by 10 -m grids.

\section{CONCLUSIONS}

- Field tests at Site 55 and OT-91 where measured concentrations using the LAPS detector agreed well with in-situ measured concentrations and concentrations determined through soil sampling.

- Field tests were conducted where application of the model predicted calibration factor provided soil concentrations that were in good agreement with the as-known concentrations.

- Calculation of MDA's for Sandia that were well below the DCGLs for U-238, Ra-226, and DU previously listed.

In data presentation, use of electronic data files allows great flexibility in presentation format to ensure effective communication and documentation. Data presentation can include electronic base maps, aerial photographs, or other electronic media that allow for ease of survey data interpretation pertinent to characterization surveys, remediation activities, or post-remediation closure surveys. Radionuclide-specific calibration factors allow data presentation to be in $\mathrm{pCi} / \mathrm{g}$, which can be compared directly to DCGLs.

In conclusion, the DoD and DOE have available a low cost method to perform radiological surveys of contaminated land areas. Using the methodology presented in this report allows for rapid determination of calibration factors for the radionuclide of concern. Detection limits demonstrated at Sandia show that this system has radionuclide-specific MDAs that will be below cleanup limits used to date for DU, U-238, Th-232, and Ra-226. MDAs can be effectively lowered when pooling of the measurements is done such as that demonstrated by averaging surface concentrations on a $10-\mathrm{m}$ by $10-\mathrm{m}$ grid. 


\section{REFERENCES}

Adams, 1999, Personal Communication; Steven Adams with Stephen Duce.

Altshuler, B. and Pasternack, B., Statistical Measures of the Lower Limit of Detection of a Radioactivity Counter, Health Physics 9:293-298; 1963.

Beck, H. L.; de Planque, G., 1968, The radiation field in air due to distributed gamma-ray sources in the ground. New York: US Atomic Energy Commission; Environmental Measurements Laboratory; Report No. HASL-195. Berger, J. D., 1992 "Manual for Conducting Radiological Surveys in Support of License Termination, Draft Report For Comment," NUREG ICR 5849, 1992.

Curie, L. A., 1968, "Limits for Qualitative Detection and Quantitative Determination Application to Radiochemistry," Analytical Chemistry 40(3):586-593.

DOE Order 5400.5, "Radiation Protection of the Public and the Environment."

Eisenbud, M., "Environmental Radioactivity" $2^{\text {nd }}$ Edition, Academic Press, NY, 1973.

Hamrick, John S., 1999, E-mail communications, RADSAFE, Frequently Asked Questions, October 21.

Helfer, I. K.; Miller, K. M., 1988, “Calibration Factors for Ge Detectors Used for Field Spectrometry," Health Physics 55:15-29.

IT Corporation (IT), 2000, "Final In-Situ Radiation Detection Demonstration General Cost and Performance Report,” February, 2000.

Miller, Mark, 2000, Personal Communication; Mark Miller with Stephen Duce.

U.S. Army Corps of Engineers (USACE), 1999, "Draft Record of Decision for the Linde Site, Tonawanda, NY," U.S. Army Corps of Engineers, Buffalo District, 1999.

U.S. Environmental Protection Agency (EPA), 1990, National Oil and Hazardous Substances Pollution Contingency Plan; final Rule; Federal Register, Volume 55, No. 46, March 8, 1990., Washington D.C.

U.S. Nuclear Regulatory Commission (NRC), 1997, "Multi-Agency Radiation Survey and Site Investigation Manual (MARSSIM)," NUREG-1575, 1997.

Osburn, W. S., Primordial Radionuclides: "Their Distribution, Movement, and Possible Effects Within Terrestrial Ecosystems” Health Physics, 11(12), 1275, 1965. 


\section{Appendix A - Sodium Iodide Detector Comparison}

This appendix compares characteristics of the LAPS detector and a sodium iodide (NaI) detector for performing in-situ surveys. In general, any radiation detector with a satisfactorily determined MDA (relative to site-specific DCGLs) can be used for the in-situ surveys described in this study. While the primary objective of this demonstration was to document the calibration factors and performance characteristics of the LAPS, additional effort was undertaken to also characterize the performance characteristics of a common 2-in by 2-in NaI detector. This was done since this detector type is commonly a part of the suite of radiation detection instruments maintained by a radiation protection organization, while the LAPS tends to be a specialty instrument owned by relatively few organizations. Comparative characteristics of the two detector types are outlined below.

\section{Plastic Scintillator}

- Energy-independent.

- Field-rugged (durable)

- Available in a variety of shapes and configurations (such as the wide detector used in this study) This enables the detector to "see" a wider area in a given survey path, requiring fewer passes to achieve 100 percent coverage of an area.

- Option of beta plus gamma sensitivity if a "beta-transparent window" is provided on the survey-face of the detector. As configured for this study the LAPS detector could detect a greater than $300 \mathrm{keV}$ beta particle.

\section{NaI Detector}

- Commonly available in inventory of radiation protection organizations.

- Relatively more sensitive than the plastic scintillator due to its higher effective atomic number $(\mathrm{Z})$.

- Field-rugged (durable).

- Energy dependent (not a factor if the site-specific contaminants are known and the instrument calibration factor has been determined).

- Detector able to "see" less width per survey path made compared to that possible with a LAPS. More passes are required to ensure that 100 percent of the area has been surveyed.

Regardless of the detector used for the site survey, it is recommended that at least 10 soil samples are collected and submitted to a laboratory for gamma spectroscopic analysis to define the radioisotopes of concern that are present at the site. These radionuclides can then be used with the calibration factors determined for the selected detector to present the final information as nominal $\mathrm{pCi} / \mathrm{g}$.

The NaI detector was used at the DOE Grand Junction Calibration pads to collect count rate data using methods similar to that used for the LAPS. At least ten count rates were recorded with the detector held centerline of each pad and at a detector height of 6, 12, and 20 in. above the pad surface. Table A.1 lists the average count rate results for these measurements. 
Table A.1

NaI Average Calibration Pad Count Rates

\begin{tabular}{|l|l|l|l|}
\hline Pad ID No. & cpm at 6 inches & cpm at 12 inches & cpm at 20 inches \\
\hline W1 & $10,430 \pm 102$ & $10,210 \pm 101$ & $10,200 \pm 101$ \\
\hline W2 & $15,820 \pm 126$ & $15,960 \pm 126$ & $15,800 \pm 126$ \\
\hline W3 & $22,90-0 \pm 151$ & $22,700 \pm 151$ & $22,300 \pm 149$ \\
\hline W4 & $29,500 \pm 171$ & $29,100 \pm 171$ & $28,200 \pm 168$ \\
\hline W5 & $27,400 \pm 166$ & $27,000 \pm 164$ & $26,300 \pm 162$ \\
\hline
\end{tabular}

The data in Table A.1 were then used to calculate the radionuclide specific calibration factors for Ra-226, Th-232, and K-40. Techniques used for these calculations were those described in Section 5.4.3.

These calibration factors are shown in Table A.2 and are approximately a factor of four lower than those listed in Table 5-9 for the LAPS detector. The difference is reflective of the effective field of view, detector volume, and intrinsic efficiency of each detector type.

Table A.2

Nal Calibration Result

\begin{tabular}{|l|l|}
\hline Ra-226 Calibration Factor & $24 \mathrm{cps} / \mathrm{pCi} / \mathrm{g}$ \\
\hline Th-232 Calibration Factor & $39 \mathrm{cps} / \mathrm{pCi} / \mathrm{g}$ \\
\hline K-40 Calibration Factor & $3.2 \mathrm{cps} / \mathrm{pCi} / \mathrm{g}$ \\
\hline \multicolumn{2}{|c|}{$\mathrm{cps}$ - counts per second } \\
pCi/g - picocuries per gram \\
NaI - sodium iodide
\end{tabular}

These calibration factors were then used in conjunction with the known radionulcide concentrations for each pad to predict the count rate expected, in cps at a detector height of $12 \mathrm{in}$. Table A.3 lists the results of this comparison. The good agreement shows that the calibration factors were correctly chosen by the method used.

Table A.3

Comparison of Predicted and Observed Count Rates

\begin{tabular}{|l|c|c|c|c|c|}
\hline & W1 & W2 & W3 & W4 & W5 \\
\hline Predicted cps & 173 & 312 & 374 & 472 & 472 \\
\hline Observed cps at 12 inches & 170 & 319 & 378 & 485 & 450 \\
\hline
\end{tabular}




\section{cps - counts per second}

Non-static MDAs were calculated as described in Section 5.4.4. However, the NaI detector has a different field of view and therefore, a different footprint angle. Assuming a footprint angle of $75^{\circ}$, the scanning MDA is given by:

$$
M D A=\frac{4.66 \sqrt{\frac{B^{*} V}{0.051+7.46^{*} H}}}{F}
$$

The MDA values for different scan speeds and radionuclides under typical field conditions are presented in Table A.4. The MDAs presented in Table A.4 were calculated using the data for the background reference pad at Grand Junction, Co., pad W-1 found in Table A.1.

Table A.4 Typical Scanning MDA Values in $\mathrm{pCi} / \mathrm{g}$

\begin{tabular}{|l|r|r|r|}
\hline Scan Speed $(\mathrm{mph})$ & 2 & 4 & 8 \\
\hline Detector Height $(\mathrm{cm})$ & 30 & 30 & 30 \\
\hline Ra-226 MDA & 1.5 & 2.2 & 3.0 \\
\hline Th-232 MDA & 0.8 & 1.1 & 1.5 \\
\hline K-40 MDA & 7.6 & 11.1 & 15.1 \\
\hline
\end{tabular}

These MDAs are very comparable to those calculated for the LAPS detector, as listed in Table 511. However, there are subtle differences that are typical of the detector material. The LAPS has the better MDA for gamma rays at the low energies (Ra-226), while the NaI has the better MDA at the high energies (K-40 with $1460 \mathrm{keV}$ ).

No angular response tests were performed on the $\mathrm{NaI}$ detector since it had no inherent shielding from gamma radiation, as was the case for the LAPS detector that was studied. It is assumed that there is no angular dependence for gamma radiation on the NaI detector, especially for the typical geometries that would be relevant to field applications during in-situ surveys.

\section{FOOTNOTES}

This work was supported by the United States Department of Energy under contract DE-AC0494AL85000. Sandia is a multi-program laboratory operated by Sandia Corporation, a Lockheed Martin Company, for the United States Department of Energy. 